\title{
Optimal Placement of PMU in Transmission Network by PSO Technique
}

\author{
Parijat Sarkar, Pinakpani Banerjee
}

\begin{abstract}
This paper presents particle swarm optimization (PSO) technique for the best allocation of phasor measurement units (PMUs) for the complete observability of connected power network. Phasor measurement units are thought-about as one of the foremost important measuring devices within the prospect of connected power network. PMUs operation may be incorporated to the wide-area connected power networks for observation and controlling functions. The optimal PMU placement (OPP) drawback provides relevance the reassurance of the least number of PMUs and their analogous locations for observability of the whole connected power networks
\end{abstract}

Index Terms - PMU, Discrete Fourier Transformation (DFT), Phasor Estimation Techniques.

\section{INTRODUCTION}

Supervisory Control and Data Acquisition (SCADA) system is being used widely for quite some time in the remote terminal unit (RTU) for monitoring of power system. But, SCADA has shortcomings i.e. the data from different locations are not taken precisely at the same instant, the magnitude of voltage (V), Active Power (P), Reactive power (Q) do not change hurriedly except under the condition of large disturbance. So, the close monitoring could not be achieved during disturbance and transients, to monitor the dynamic behavior of the system, faster and synchronized data is required. PMU's overcome the above shortcomings and give time synchronized phasor values of voltages $\&$ currents.

\section{NEED FOR PMU}

Real-time monitoring of grid has become essential for maintaining reliability and stability of the power system. Phasor Measurement Units (PMU) are the modern sensing devices which do the above mentioned work efficiently. PMU is a device which measures 'Magnitude' \& 'Phase' of the electrical waves on an electricity grid using a common time source for synchronization i.e. time stamping using GPS.The PMU sends signal in form of a time stamped phasor to a local or remote receiver at rates up to $60 \mathrm{sample} / \mathrm{sec}$. Observability with respect to voltage, current and power flow at every bus is of utmost importance for analysing the status of the system at any given moment of time. PMU help in making the grid completely observable. At present PMUs are

Parijat Sarkar, School Of Electrical Engineering, Kiit University, Bhubaneswar, India

Pinakpani Banerjee, School Of Electrical Engineering, Kiit University, Bhubanewar, India costly to be placed at every bus in the system. Therefore, the number of PMUs needs to be kept minimum so that costing can be as low as possible. Complete observability by using minimum numbers of PMU in a network is taken care by the optimization techniques

\section{BLOCK DIAGRAM OF PMU}

The basic structure of PMU is given in Fig. 1. It consists of Synchronization Unit, Measurement Unit and Data Transmission Unit [71].

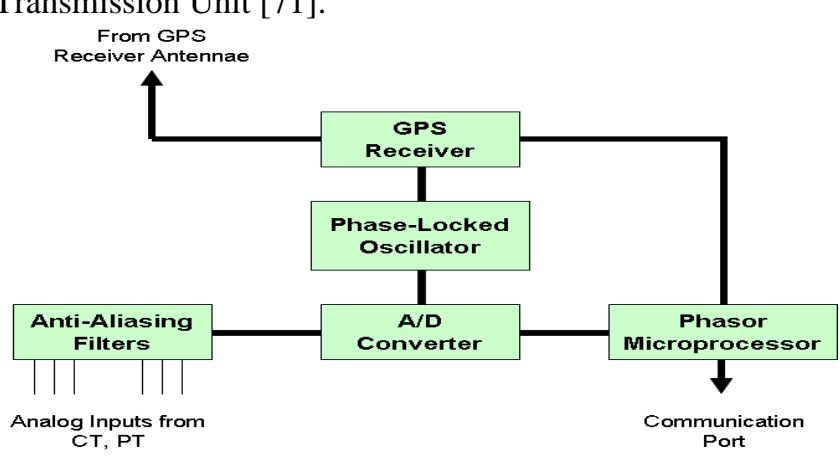

Fig-1 PMU Block Diagram

The Clock Synchronization Unit provides a common sampling clock to the Measurement Unit. GPS time stamping by GPS receivers and phase-locked oscillators provide a theoretically accurate synchronization [62,109]. An output signal is generated by a control system to compare it with the phase of an input signal. A variable frequency oscillator and a phase detector compare the phases of the two signals.

The Measurement Unit consist of Anti-aliasing filters, Analog-to-Digital Convertor (ADC) and Processor. A signal is passed through an Anti-aliasing filter which assures that the phase angle differences and relative magnitudes of all the signals remain unchanged. Out of various available filters, Butterworth filter is preferred due to its flat response in pass-band [110]. Thereafter, the analog signal is converted to digital signal by ADC [109]. Large number of PMUs deployed in a wide area network help in full visibility of the network system by use of such synchronized measurements. Simulation software's such as MATLAB or Lab VIEW are used for PMU modeling and check the algorithms meant for the phasor estimation techniques [112-113].

Finally, the data is transmitted by the Data Transmission Unit with the help of a MODEM (modulator-demodulator). A MODEM's function is to modulate as well as demodulate a signal. MODEM can be used for transmitting more than one analog signal at a time. 


\section{PMU MODELLING}

The modelling of PMU is done by using DFT Non-recursive Algorithm with the help of NI LabVIEW software.

i. Phasor Estimation Technique

There are various methods used for phasor estimation, some of them are Zero Crossing, Discrete Fourier Transformation (DFT), Sliding DFT, Least Error Squares, Kalman Filters, Demodulation and Phasor measurement angle changing.

ii. Discrete Fourier Transformation (DFT)

DFT technique has been implemented in the present work for modelling of PMU with the help of NI LabVIEW software. DFT is used when the signals are known only at $\mathrm{N}$ instants separated by a sample times T(i.e. a finite sequence of data). DFT converts a time domain signal to frequency domain without making any changes in the information carried by the input signal. DFT has two types of estimation techniques depending upon the use of data from the previous window. The two types of algorithms are recursive and non-recursive .The recursive DFT algorithm takes the reference of previous data window while the non-recursive algorithm does not take any reference of previous data. Therefore, recursive DFT algorithm computational time is more and is therefore rather unstable. While the Non-recursive DFT algorithm requires relatively lesser computational time and is therefore more stable. Due to stability and simplicity, non-recursive has been used in the present work for modelling of PMU.

iii. Non-Recursive DFT Algorithm

In non-recursive DFT (NDFT) algorithm all the phasor estimate are considered from a fresh window and the reference from previous window data are not considered. A sinusoid can be written as in (4.1).

$$
\mathrm{x}(\mathrm{t})=\sqrt{2} \mathrm{X}(\sin \omega \mathrm{t}+\varphi)
$$

The above sinusoid is represented in Phasor form as mentioned below in (2)

$$
X=X \_m e^{\wedge} j \varphi=X \_m(\cos \varphi+j \sin \varphi)
$$

If, $M$ is number of samples per cycle in a $50 \mathrm{~Hz}$ signal then the phasor estimate is given by the (4.3) below:

$$
\begin{gathered}
\mathrm{x} \_\mathrm{m}=\sqrt{ } \quad 2 \quad \sin \theta(2 \pi \mathrm{m} / \mathrm{M}+\varphi)=\sqrt{ } \quad 2 \\
\sin \theta(\theta \mathrm{m}+\varphi)
\end{gathered}
$$

where, $\theta=2 \pi / \mathrm{M}=$ Sampling Angle

Therefore, phasor estimate of successive window of Mth and (M-1)th phasor samples are given below in (4.4) and (4.5):

$$
\begin{aligned}
& x_{m}=\frac{\sqrt{2}}{M} \sum_{m=0}^{M-1} x_{m+1} \cdot e^{-j \theta_{m}} \\
& x_{m-1}=\frac{\sqrt{2}}{M} \sum_{m=0}^{M-1} x_{m} \cdot e^{-j \theta_{m}}
\end{aligned}
$$

The sampling frequency is $\mathrm{M}$ multiplied to fundamental frequency. The two successive windows of sample (m) and (m-1) are selected and the phasor values are calculated by using NDFT algorithm.

Mathematically, let the number of samples (M) is 12 , so sampling angle $\theta=(2 \pi / 12)=30^{\circ}$. Let, $\varphi$ is the angle for first sample window and is equal to $30^{\circ}$. Then, next sample window will have angle $(\varphi+\theta)$ i.e. $60^{\circ}$ and so on. Final phasor estimate is obtained by averaging all the phasor values. It shows that there is no change in the magnitude of the phasor value while the phase angle $\theta$ only changes for each window in anticlockwise direction by an angle equal to sampling angle. The flowchart of non-recursive DFT algorithm is shown in the Fig. 2.

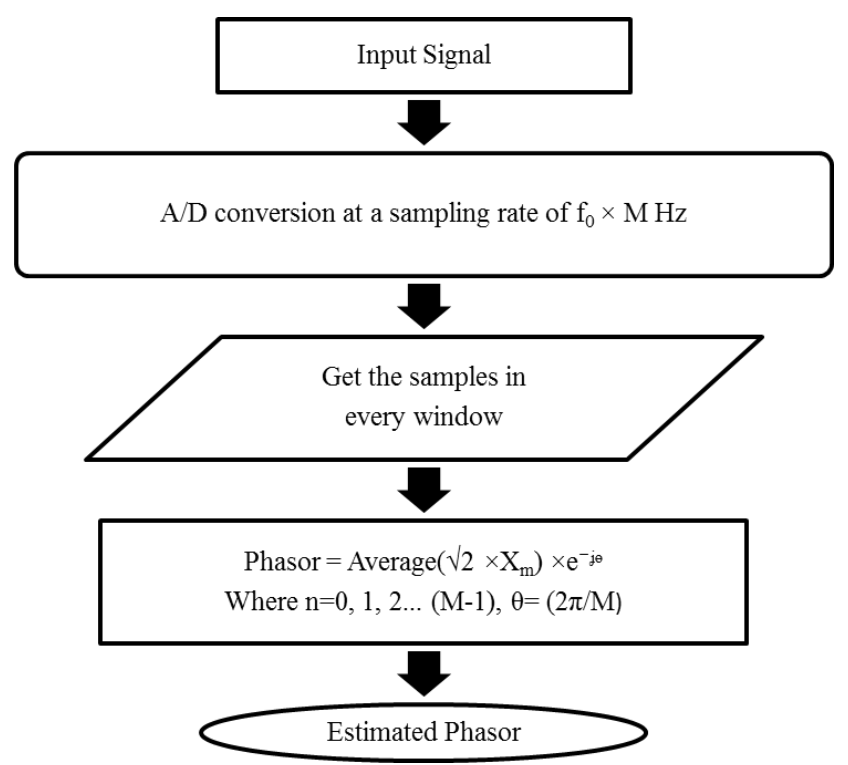

Fig.2. Flowchart for Non-recursive DFT Algorithm

\section{V.PMU MODELLING WITH LABVIEW}

LabVIEW software from National Instruments has been used for modelling and simulation of PMU. In the algorithm used for non-recursive DFT phasor estimation, the input signal is generated from LabVIEW library. Real time signal can also use from any data acquisition platform which is compliant with LabVIEW such as NI cRIO. As per the algorithm used, the phasor estimate is presented in polar form along with the complex output. The algorithm is repeated for successive data samples. When a new phasor estimate for the given phasor is taken, the phasor rotates anticlockwise by an angle $\Theta$, sampling angle which is delay in getting successive sample. The non-recursive LabVIEW model is given in the Fig. 3, which shows both Front panel and Block diagram of the model. 
International Journal of New Technology and Research (IJNTR) ISSN:2454-4116, Volume-4, Issue-11, November 2018 Pages 10-15

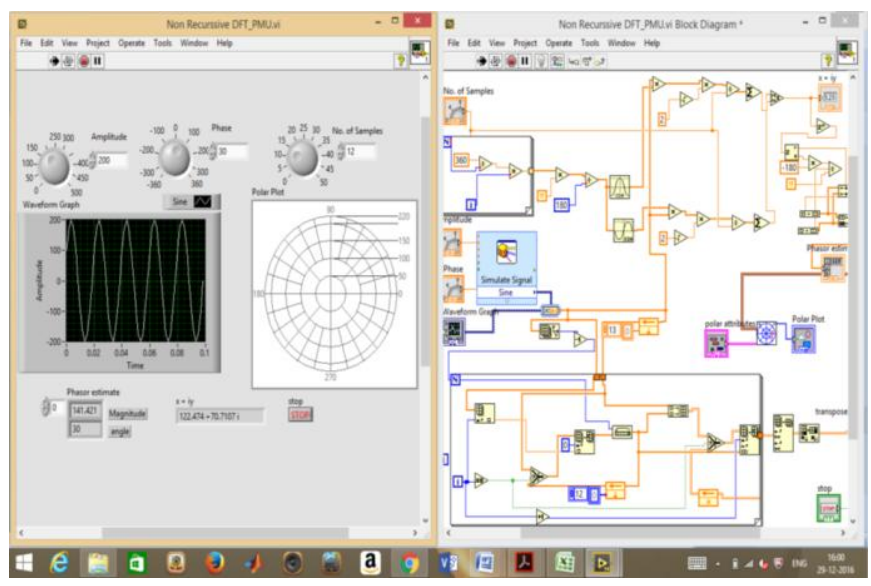

Fig. 3. LabView Model for Single Phase Non-recursive Algorithm

\section{PMU MODEL SIMULATION VALIDATED WITH MATHEMATICAL ANALYSIS}

In the Fig. 4.3, knobs are provided in the Front panel to change the values of magnitude, phase angle of the input signal and number of samples so that the model can be tested in all the conditions. For simulating a test case , a single phase $230 \mathrm{~V}, 50 \mathrm{~Hz}$ system is assumed with a signal given below,

$$
X(t)=200 \cos (100 \pi t+\pi / 6)
$$

The sampling frequency is taken as $600 \mathrm{~Hz}$ which is 12 samples per cycle. The data window is of 12 samples. It was found that the phasor estimation performed over first waveform cycle of sinusoid i.e. first 12 samples or one complete first cycle has a phasor value $141.421 / 30^{\circ}$ as given in Table 4.1. Thereafter, first 20 samples are obtained and phasor values are evaluated as per algorithm flowchart mentioned in Fig. 4.2. The phasor value as calculated by the use of algorithm is given in the Table 4.2.

Table 4.1 Phasor estimate of the first phasor

\begin{tabular}{|c|c|c|c|}
\hline \multicolumn{4}{|c|}{$V(t)=200 \cos (100 \pi t+\pi / 6), N=12$, Sampling Frequency $=600 \mathrm{~Hz}$} \\
\hline Sample No. (n) & Sample V(m) & $\mathrm{v} 2{ }^{*} \mathrm{e}^{(-\mathrm{jm} \theta)}$ & $\mathrm{V}(\mathrm{m})^{*} \mathrm{v} 2^{*} \mathrm{e}^{(-\mathrm{jm} \mathrm{m})}$ \\
\hline 0 & 173.2 & $1.4142+j 0.0000$ & $244.9394+j 0.0000$ \\
\hline 1 & 100 & $1.2247-j 0.7071$ & $122.4762+\mathrm{j} 70.7101$ \\
\hline 2 & 0 & $0.7071-j 1.2247$ & $0.0000+j 0.0000$ \\
\hline 3 & -100 & $0.0000-\mathrm{j} 1.4142$ & $0.0000+j 141.4213$ \\
\hline 4 & -173.2 & $-0.7071-j 1.2247$ & $122.4697+j 212.1180$ \\
\hline 5 & -200 & $-1.2247-j 0.7071$ & $244.94+\mathrm{j} 141.42$ \\
\hline 6 & -173.2 & $-1.4142-j 0.0000$ & $244.9394+j 0.0000$ \\
\hline 7 & -100 & $-1.2247+j 0.7071$ & $122.4762+j 70.7101$ \\
\hline 8 & 0 & $-0.7071+j 1.2247$ & $0.0000+j 0.0000$ \\
\hline 9 & 100 & $0.0000+j 1.4142$ & $0.0000+j 141.4213$ \\
\hline 10 & 173.2 & $0.7071+j 1.2247$ & $122.4697+j 212.1180$ \\
\hline 11 & 200 & $1.2247+j 0.7071$ & $244.94+j 141.42$ \\
\hline \multicolumn{4}{|c|}{$\mathrm{SUM}=1469.6797+j 848.520$} \\
\hline \multicolumn{4}{|c|}{ Average $=122.4733+j 70.71=141.421 / 30^{\circ}$} \\
\hline
\end{tabular}

Table 4.2 Phasor estimate of sampling windows

\begin{tabular}{|c|c|c|c|}
\hline Sample No. (n) & SampleX(m) & $\begin{array}{c}\text { Phasor Estimate by using } \\
\text { Non-Recursive DFT } \\
\text { Algorithm }\end{array}$ & Remarks \\
\hline 0 & 173.20 & $141.421 / 30^{\circ}$ & \multirow{12}{*}{$\begin{array}{l}\text { First } 12 \text { samples calculated } \\
\text { by using Non-Recursive } \\
\text { DFT Algorithm and are } \\
\text { found to be same } \\
\text { i.e. } 141.421 / 30^{\circ}\end{array}$} \\
\hline 1 & 100.00 & $141.421 / 30^{\circ}$ & \\
\hline 2 & 000.00 & $141.421 / 30^{\circ}$ & \\
\hline 3 & -100.00 & $141.421 / 30^{\circ}$ & \\
\hline 4 & -173.20 & $141.421 / 30^{\circ}$ & \\
\hline 5 & -200.00 & $141.421 / 30^{\circ}$ & \\
\hline 6 & -173.20 & $141.421 / 30^{\circ}$ & \\
\hline 7 & -100.00 & $141.421 / 30^{\circ}$ & \\
\hline 8 & 000.00 & $141.421 / 30^{\circ}$ & \\
\hline 9 & 100.00 & $141.421 / 30^{\circ}$ & \\
\hline 10 & 173.20 & $141.421 / 30^{\circ}$ & \\
\hline 11 & 200.00 & $141.421 / 30^{\circ}$ & \\
\hline 12 & 173.20 & $141.421 / 60^{\circ}$ & \multirow{9}{*}{$\begin{array}{l}\text { After } 12^{\text {th }} \text { sample the } \\
\text { magnitude remain constant } \\
\text {,only angle changes. }\end{array}$} \\
\hline 13 & 100.00 & $141.421 / 90^{\circ}$ & \\
\hline 14 & 000.00 & $141.421120^{\circ}$ & \\
\hline 15 & -100.00 & $141.421 / 150^{\circ}$ & \\
\hline 16 & -173.20 & $141.421 / 180^{\circ}$ & \\
\hline 17 & -200.00 & $141.421 / 210^{\circ}$ & \\
\hline 18 & -173.20 & $141.421 / 240^{\circ}$ & \\
\hline 19 & -100.00 & $141.421 / 270^{\circ}$ & \\
\hline 20 & 000.00 & $141.421 / 300^{\circ}$ & \\
\hline
\end{tabular}

The phasor output in polar form obtained from LabVIEW simulation are shown in Fig. 4.4 and Fig. 4.5. From Fig.4.5, it is concluded that the new phasor shifted by 30 degrees anticlockwise from the phasor in Fig. 4.4

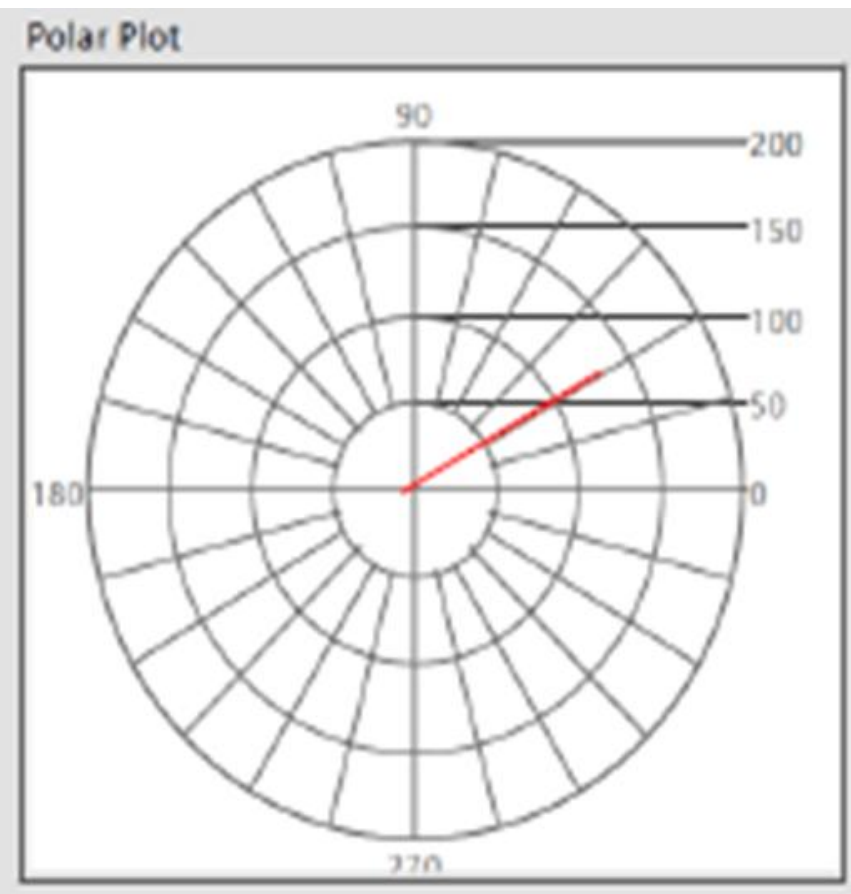

Fig. 4. Phasor estimation using Non-recursive algorithm for first data window 


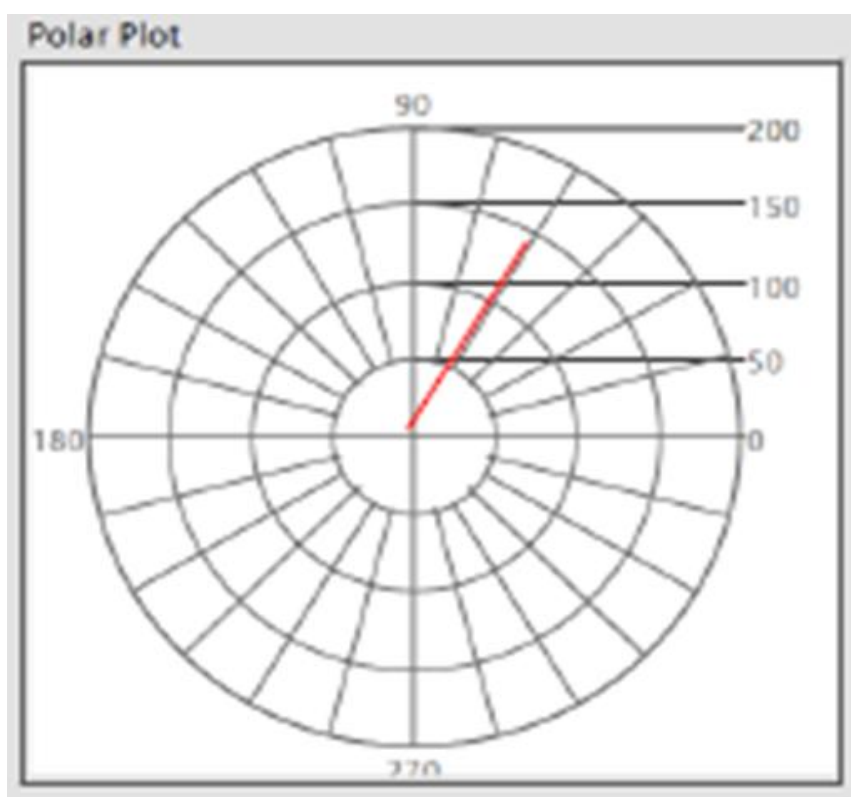

Fig. 5. Phasor estimation using Non-recursive algorithm for second data window

\section{PROBLEM FORMULATION}

The problem is stated as optimal placement of PMU in a transmission network by using proposed heuristic techniques References

\section{OPTIMAL PLACEMENT OF PMU}

Optimum placement of PMU is needed to keep the number of PMUs minimum due to high cost while maintaining the complete observability of a power network. Particle Swarm Optimization (PSO) and Teaching-Learning-Based optimization (TLBO) technique are used for optimal placement of PMU in a IEEE 39 bus system. The result of better technique has been used in the subsequent studies.

\section{PMU PLACEMENT CONDITIONS}

In order to find the optimal location of phasor measurement units, information about network structure and bus types is sufficient. The condition of connectivity of the buses and transmission lines is determined by the incident Matrix network. In other words, if $\mathrm{A}$ is incident Matrix and $\mathrm{n}$ is the number of buses; A is a matrix that its arrays are as follow in (4.6)

$$
A_{n \times n}(i, j)= \begin{cases}1 & i=j \\ 1 & \text { if buses } i \text { and } j \text { are connected } \\ 0 & \text { otherwise }\end{cases}
$$

Where, $i$ is the index for source bus and $\mathrm{j}$ refers to end bus for each line. Because of the nonlinear nature of the PMUs placement problem, the vector of $X$ is in the form of (4.7):

$$
[X]_{i}=X_{i}=\left\{\begin{array}{ll}
1 & \text { if a PMU is installed at bus } \mathrm{i} \\
0 & \text { otherwise }
\end{array}\right\}
$$

Since, each number of $\mathrm{X}$ shows the installation or un-installation state of PMUs and the goal is to find the minimum number of buses for the observability of the whole power system, the objective function can be considered as below in (4.8): $\min \sum_{i=1}^{N} X_{i}$

where, $\mathrm{N}$ is the number of buses and $\mathrm{X} \_\mathrm{i}$ is the minimum number of buses considered for network observability.

Since, the bus with at least one PMU placed on it and the buses connected to such bus is considered observable. Therefore, observability objective function can be defined as follow (4.9):

$$
f_{i}=\sum_{j=1}^{N} A_{i j} X_{j} \geq 1 \quad, \quad \mathrm{i}=1,2, \ldots, N
$$

Where, is requirement for system observability in each bus. The digit 1 in right side of the equation guarantees that at least one of the appeared variables in the summation will be non-zero.

\section{SYSTEM USED - IEEE 39 BUS SYSTEM}

The 39 bus grid includes 34 transmission lines, 10 generators, and 12 transformers at the frequency of $50 \mathrm{~Hz}$ [42]. For the dynamic simulation purposes, the fifth-order model of synchronous machines with IEEE_DC type 1 for excitation. Loads are modeled as static at all the buses, except buses 3 and 18 , which are considered dynamic loads using induction motors in simulations. The detailed technical specification of 39 bus system used is given in Appendix A.

\section{Solution Methodology}

The problem has been solved by using the techniques stated as below.

\section{Optimum Placement of PMU by Particle Swarm Optimization (PSO)}

PSO principle is inspired by the social behaviour of a group of birds making a formation during their flight or the way fishes make a pattern while swimming in the ocean. The system initialization takes place by a population of random solutions and searches for optima by updating generations [108]. the particle swarm algorithm is given below:

Step 1: For each particle initialize position and velocity.

Step 2: For each particle, calculate fitness value.

If the fitness value is better than its personal best, set current value as the new pbest.

Choose the particle with the best fitness value of all as gbest.

For each particle, calculate particle velocity and update the particle location.

Step3: If maximum iterations or minimum error criteria is attained, STOP.

Else, repeat next iteration.

After finding the two best values pbest [ ] and gbest [ ], the particle updates its velocity and positions (4.10) to (4.12):

$\mathrm{v}(\mathrm{t}+1)=\mathrm{W} \cdot\left\{\mathrm{v}(\mathrm{t})+\mathrm{c} \_1\right.$.rand $(1) \cdot($ pbest [

])+c_2.rand(2).(gbest[ ]-p[ ]\}

$\mathrm{p}(\mathrm{t}+1)=\mathrm{p}(\mathrm{t})+\mathrm{v}(\mathrm{t}+1)$

Where,

$$
\mathrm{W}=2 /\left|2-\mathrm{c}-\sqrt{ }\left(\mathrm{c}^{\wedge} 2-4 \mathrm{c}\right)\right| \text { and } \mathrm{c} 1+\mathrm{c} 2=\mathrm{c}>4
$$

In the above equations, $v(t)$ represents the velocity of the particle, $p(t)$ is the position of the particle (PMU placement) for the iteration number $\mathrm{t} . \mathrm{c} 1, \mathrm{c} 2$ are the acceleration 
International Journal of New Technology and Research (IJNTR)

ISSN:2454-4116, Volume-4, Issue-11, November 2018 Pages 10-15

constants of the particle which control the movement of each particle towards its individual and global best position.

$\mathrm{W}$ is the inertia constant which improves the convergence rate, rand1, rand 2 are the random numbers between $(0,1)$. The flowchart of the Swarm Algorithm is given in Fig. 6.

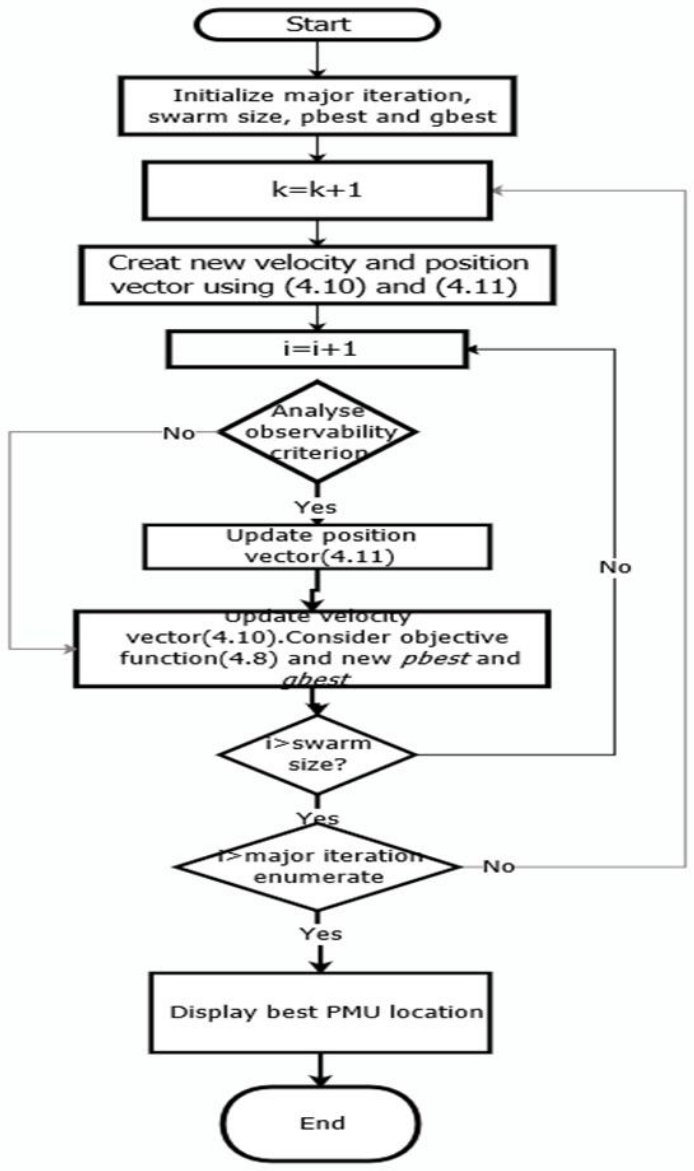

Fig. 6. Flowchart showing the PSO technique

\section{Simulation Results OF OPTIMAL PMU PlaCEMENT (OPP)}

THE PARAMETERS USED IN THE OPTIMIZATION TECHNIQUES FOR PMU LOCATION ARE GIVEN IN TABLE 4.3.

Table 4.3 Parameters for the presented optimization techniques

\begin{tabular}{|c|c|}
\hline Parameters & Values \\
\hline Population size $(\mathrm{p})$ & 40 \\
\hline Acceleration factor/ Cognitive par ameter $\left(\mathrm{c}_{1}\right)$ & 2 \\
\hline Acceleration factor/ Social parameter $\left(\mathrm{c}_{2}\right)$ & 2 \\
\hline Random number $\left(\mathrm{r}_{1}\right.$ andr $\left.\mathrm{f}_{2}\right)$ & O? ri? $1, \mathrm{i}=1,2$ \\
\hline Inertia weight $\left(\mathrm{w}_{\max }\right)$ & 0.9 \\
\hline Inertia weight $\left(\mathrm{w}_{\min }\right)$ & 0.4 \\
\hline Number of variables $(\mathrm{m})$ & 3 \\
\hline maximum number of iteration $($ maxite $)$ & 1000 \\
\hline
\end{tabular}

Table 4.4 below shows the result of optimization for position of PMUs by using PSO and TLBO techniques with the objective to have full observability of the system using minimum quantity of PMU.

\begin{tabular}{|c|c|c|c|c|}
\hline \multicolumn{2}{|c}{ Table 4.4 Optimal Location of PMUs in a IEEE 39 bus system Under Normal Operation } \\
\hline Test System & $\begin{array}{c}\text { Optimal Location of } \\
\text { PMU as per PSO }\end{array}$ & $\begin{array}{c}\text { Optimal No. Of } \\
\text { PMUs by PSO }\end{array}$ & $\begin{array}{c}\text { Optimal Location of PMU } \\
\text { as per TLBO }\end{array}$ & $\begin{array}{c}\text { Optimal No. Of } \\
\text { PMU by TLBO }\end{array}$ \\
\hline No-ZIB & $\begin{array}{c}2,4,6,9,10,13,16,17,19, \\
22,23,29,37\end{array}$ & 13 & $\begin{array}{c}2,4,5,5,12,16,18,26,32,33,3 \\
4,35,36,37,38,39\end{array}$ & 16 \\
\hline ZIB & $3,8,12,16,23,29,34,37$ & 8 & $3,8,12,16,23,29,34,37$ & 8 \\
\hline
\end{tabular}

\section{RESULT ANALYSIS}

When an optimization algorithm selects a bus for placing the PMU, it is assumed that all the directly connected buses automatically are in the range of the placed PMU. Therefore, for a practical system, results are shown for both when Zero Injection Bus (ZIB) is considered as well as when it was not considered. For optimizing the number of PMUs in the system, number of iterations for both PSO and TLBO technique is taken as same for checking their convergence efficiency where PSO was found to be $20 \%$ more effective than TLBO. For same objective function and same number of iterations, PSO converges to lesser number of PMUs than the TLBO method in the IEEE 39 bus system. Therefore, the result obtained by using the PSO technique has been selected for further study.

In the 39 bus system (as shown in Fig.7), the location of each PMU has been optimized by using PSO algorithm for making the system observable.

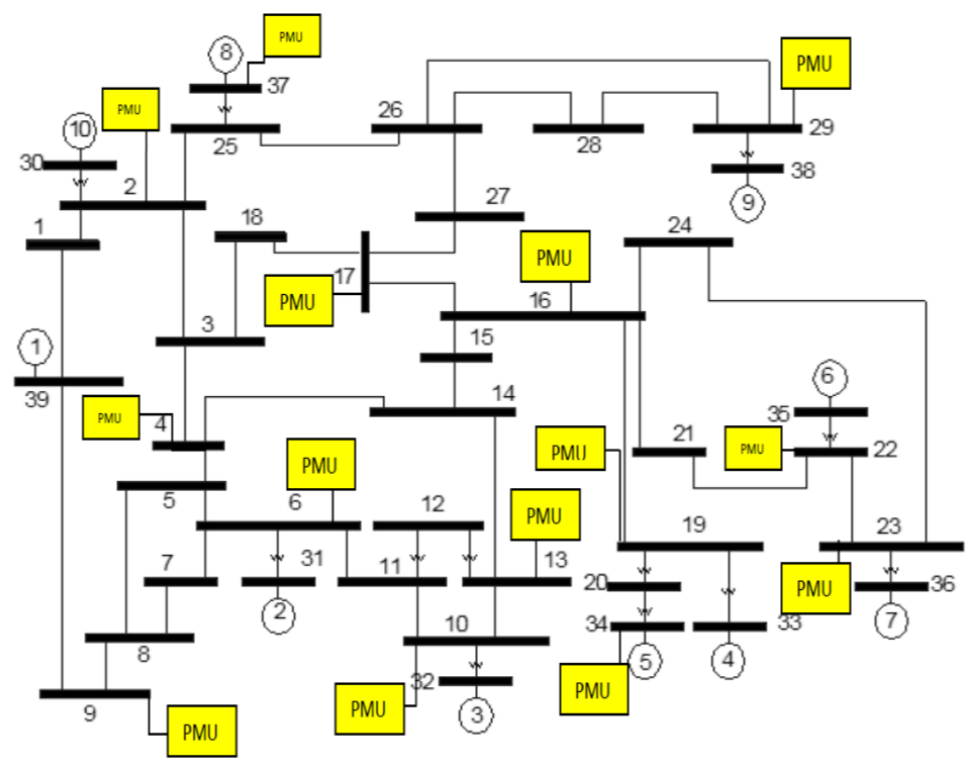

Fig. 7. Optimal PMU placement using PSO 


\section{CONCLUSION}

For full observability in a 39 bus system, the optimal PMU placement is simulated using PSO optimization techniques and it was concluded that the PSO technique converges to a solution which is better any other method by $20 \%$ approximately when there is no zero injection bus (ZIB) keeping all the parameters and constraints same.

\section{REFERENCES}

[1] Pereira, R., et al. "Consumer energy management system with integration of smart meters." Energy Reports 1: pp. 22-29, 2015.

[2] FICCI (2013). India Smart Grid Day, India Smart Grid[Online].Available:

http://indiasmartgrid.org/en/Documents/Context of Smart grids in India-Knowledge paper of India Smart Grid Day2013.pdf

[3] Nthontho, Monontsi; Chowdhury, S. P.; Winberg, Simon; "Smart communication networks standards for smart energy management", Telecommunications Energy Conference (INTELEC), 2011 IEEE 33rd International.

[4] T. Van Cutsem, T. Vournas; Voltage Stability of Electric Power System, Norwell, MA: Kluwer, 1998.

[5] IEEE Std 1410-2010, IEEE Guide for improving the lightning performance of electric power overhead distribution lines, 2011.

[6] Han J, Seo HC, Kim CH, Analysis of lightning overvoltage according to the location of overhead ground wire in Korea distribution system, 2012 IEEE Vehicle Power and Propulsion Conference (VPPC), Seoul, Korea, pp. 1274- 1276, 2012.

[7] Gupta B.R. Generation of Electrical Energy, New Delhi: S. Chand and Company Limited, 2016. Print

[8] S.C. Bhattacharyya, "An overview of problems and prospects for the Indian power sector", Energy, vol. 19, Issue 7, 1999, pp. 795-803.

[9] Y. R. Sood, N. P. Padhy, and H. O. Gupta, "Deregulated Model and Locational Marginal Pricing," Electrical Power System Research, vol. 77, issue 5-6, pp. 574-582, 2010.

[10] Duan, Y., R. G. Harley, and T. G. Habetler. "Comparison of particle swarm optimization and genetic algorithm in the design of permanent magnet motors." Power Electronics and Motion Control Conference, 2009. IPEMC'09. IEEE 6th International. IEEE, 2009.

[11] Hajian, Mahdi, et al. "Optimal placement of PMUs to maintain network observability using a modified BPSO algorithm." International Journal of Electrical Power \& Energy Systems 33.1 (2011): 28-34.

[12] S. Chakrabarti and E. Kyriakides, "Optimal placement of phasor measurement units for power system observability," IEEE Trans. Power Syst., vol. 23, no. 3, pp. 1433-1440, Aug. 2008.

[13] B. Leonardi, and V. Ajjarapu, "An Approach for Real Time Voltage Stability Margin Control via Reactive Power Reserve Sensitivities," IEEE Transaction. Power Systems, vol. 28, no. 4, Nov 2013.

[14] K. Seethalekshmi, S.N. Singh, S.C. Srivastava, "A Synchrophasor Assisted Frequency and Voltage Stability Based Load Shedding Scheme for Self-Healing of Power System," IEEE Transaction. Smart Grid, vol. 2, no. 2, June 2011

[15] Wang, Yang, et al. "Incorporating generator equivalent model into voltage stability analysis." IEEE transactions on Power Systems 28.4 (2013): 4857-4866

[16] Wikipedia, The Free Encyclopedia (2011) "Harmonics (electrical power),"

[Online].Available: https://en.wikipedia.org/wiki/Harmonics_(electrical_power)

[17] Dugan, Roger C, and Roger C. Dugan. Electrical Power Systems Quality. New York: McGraw-Hill, 2003. Print.

[18] REN21 Steering Committee. "Renewable 2009, Global Status Report," World watch Institute Washington, DC, 2009.

[19] Puttgen, H.B.; MacGregor, P.R.; Lambert, F.C., "Distributed generation:Semantic hype or the dawn of a new era", Power and Energy Magazine,IEEE, vol.1, no.1, pp. 22-29, Jan Feb 2003.

[20] Lassetter, R., Abbas Akhil, and Chris Marnay. "White paper on integration of distributed energy resources-the CERTS microgrid concept." 2003-10]. http://certs. lbl. gov/pdf/50829. pdf (2002).

[21] Langella, R., and A. Testa. "IEEE Recommended Practice and Requirements for Harmonic Control in Electric Power Systems." IEEE STANDARD 519-2014, IEEE Power and Energy Society, 2014.

[22] The Electricity (Amendment) Bill, 2014 of India, section 2 ,clause (1A),pp. 1, 2014.

[23] The Indian Electricity Grid Code of CERC, Operating code (Chapter-6) section 6.2, 2002.
[24] National Instrument, "Operating Instruments and Specifications: CompactRIO cRIO-9082," 2013.

[25] dSPACE DS1104. Hardware Installation and Configuration and Control Desk Experiment Guide, Paderborn, Germany, 2008.

[26] National Insruments, "Getting Started with LabVIEW," 2014.

[27] T. Eastham, "Reactive Power Control in Electric Systems," New York: Whiley, 1982.

[28] Z. H. Rather, Z. Chen, P. Thøgersen, P. Lund and B. Kirby, "Realistic Approach for Phasor Measurement Unit Placement: Consideration of Practical Hidden Costs," in IEEE Transactions on Power Delivery, vol. 30, no. 1, pp. 3-15, Feb. 2015.

[29] D. G. Hart, V. Gharpure, D. Novosel, D. Karlsson, M. Kaba, "PMUs A new approach to power network monitoring", ABB Review 1/2001

[30] Mathworks http://in.mathworks.com/help/signal/ref/butter.html.

[31] Xu, Li, and Degang Chen. "ADC spectral testing allowing amplitude clipping", 2013 IEEE International Instrumentation and Measurement Technology Conference (I2MTC), 2013.

[32] Vinay K. Ingle, John G. Proakis, "Digital Signal Processing Using MATLAB $)^{\prime}$ ", Third Edition, Cengage Learning, USA, 2012

[33] Tadej TAŠNER, Darko LOVREC, Frančišek TAŠNER, Jörg EDLER, "Comparison of LabVIEW and MATLAB for Scientific Research" ,International Journal of Engineering, Fascicule 3. pp-389-394, Tome $\mathrm{X}$ (Year 2012)

[34] Essays, UK. (November 2013). PSO Based Algorithm for Optimal PMU Placement in KPTC. Retrieved from https://www.ukessays.com/essays/engineering/a-pso-based-cluster-for mation.php?vref=1 